\title{
Examination of carbon partitioning into austenite during tempering of bainite
}

\author{
F.G. Caballero ${ }^{1}$, M.K. Miller ${ }^{2}$, A.J. Clarke ${ }^{3}$ and C. Garcia-Mateo ${ }^{1}$ \\ ${ }^{1}$ Department of Physical Metallurgy, Centro Nacional de Investigaciones Metalúrgicas \\ (CENIM-CSIC), Avda. Gregorio del Amo, 8. E-28040 Madrid, Spain \\ 2 Oak Ridge National Laboratory, Materials Science and Technology Division, P. O. \\ Box 2008, Oak Ridge, TN 37831-6136, USA \\ ${ }^{3}$ Materials Science and Technology Division, Mail Stop G770, Los Alamos National \\ Laboratory, Los Alamos, NM 87545, USA
}

Keywords: bainitic steels, tempering, atom probe tomography, carbon partitioning, quenching and partitioning

\begin{abstract}
.-
The redistribution of carbon after tempering of a novel nanocrystalline bainitic steel consisting of a mixture of supersaturated ferrite and retained austenite has been analyzed by atom probe tomography. No direct evidence supporting the additional carbon enrichment of austenite beyond that initially achieved during the bainite heat treatment was obtained during subsequent tempering of this high carbon, high silicon steel.
\end{abstract}

The martensite transformation is universally accepted to involve diffusionless growth of ferrite, which is supersaturated with carbon at low temperature. For many years, it has been recognized that carbon may partition from martensite to austenite after transformation, because the solubility of carbon is much greater in austenite [1,2]. Although the existence of carbon-enriched retained austenite in martensitic steel microstructures has been known for some time [3], the process of partitioning from the supersaturated martensite to the untransformed austenite has received little attention in quenched steels. Recently, a new processing concept known as quenching and partitioning (Q\&P) has been proposed [4-6] for designing high strength, ductile steels [7]. This process involves quenching austenite below the martensite-start temperature, followed by a partitioning treatment to enrich the remaining austenite with carbon, thereby stabilizing it to room temperature [4-7].

Clarke et al. [8] proposed two possible mechanisms for austenite carbon enrichment of a Fe- 0.19 wt.\% C-1.59\% Mn-1.63\% Si steel subjected to Q\&P processing, including: (i) the partitioning of carbon to untransformed austenite from carbon supersaturated martensite and (ii) the carbon enrichment of austenite associated with the formation of carbide-free bainite. Theoretical calculations [8] showed the partitioning of carbon to austenite from the initial martensite was more consistent with the experimental austenite fraction results. Deviation from the predicted results suggested the loss of carbon atoms to competing processes, such as carbide precipitation or carbon segregation to dislocations [7].

The details of carbon partitioning during the bainite transformation have traditionally been somewhat more controversial. However, the determination of the carbon concentrations in bainitic ferrite by atom probe tomography (APT) in a high carbon, 
high silicon nanocrystalline bainitic steel with extremely slow bainite transformation kinetics at $200{ }^{\circ} \mathrm{C}$ has recently demonstrated carbon supersaturation of the bainitic ferrite at the earliest stage of transformation [9]. Results have indicated that iron and substitutional atoms, such as manganese, chromium and silicon, do not diffuse during the bainite transformation, but the partitioning of carbon into the residual austenite occurs immediately after formation [9]. The bainite reaction ceases well before the austenite carbon content reaches para-equilibrium (PE). Moreover, APT revealed a substantial quantity of carbon trapped at dislocations in the vicinity of the ferriteaustenite interface, which prevents the complete decarburization of supersaturated ferrite [10].

Previous work on the redistribution of substitutional elements during tempering of the same nanocrystalline steel suggested that retained austenite decomposes before full equilibrium is reached at the interface [11]. Although partitioning of chromium across the interface was observed after tempering at $450{ }^{\circ} \mathrm{C}$ for $30 \mathrm{~min}$., there was no clear indication of silicon or manganese partitioning across the austenite/bainitic ferrite interface. In this study, carbon partitioning across the austenite/supersaturated ferrite interface was analyzed by APT after tempering to seek direct, supporting evidence for additional austenite enrichment before carbide precipitation. A two-stage heat treatment, consisting of an initial austempering was used to produce nano-scale plates of bainitic ferrite and carbon-enriched retained austenite, where carbon partitioning occurs from supersaturated bainitic ferrite to austenite, followed by water quenching and subsequent reheating and tempering. This process differs from the Q\&P process, where carbon partitioning from initially supersaturated martensite to austenite occurs during the partitioning step after the first quenching step below the martensite start temperature.

In the current study, a high carbon, high silicon steel is investigated, whereas recent Q\&P heat treatments have been performed with a low carbon, high silicon steel [7]. Regardless, the results may help to elucidate whether carbon partitioning from supersaturated ferrite to austenite occurs during tempering.

Homogenized specimens of Fe-0.98 wt.\% C-1.46\% Si-1.89\% Mn-1.26\% Cr-0.26\% Mo-0.09\% V (Fe-4.34 at.\% C-2.76\% Si-1.82\% Mn-1.28\% Cr-0.146\% Mo-0.09\% V) were austenitized for $15 \mathrm{~min}$. at $1000{ }^{\circ} \mathrm{C}$, and then isothermally transformed in the bainitic temperature region $\left(\mathrm{M}_{\mathrm{S}}=120^{\circ} \mathrm{C}\right.$; and $\left.\mathrm{B}_{\mathrm{S}}=350{ }^{\circ} \mathrm{C}\right)$ at $200{ }^{\circ} \mathrm{C}$ for 10 days before quenching into water. This microstructure was then tempered at 400 and $450{ }^{\circ} \mathrm{C}$ for 30 min.

APT specimens were electropolished using the standard double layer and micropolishing methods [12]. Atom probe analyses were performed in the voltage-pulse mode in an Imago Scientific Instruments local electrode atom probe (LEAP ${ }^{\circledR}$ 2017) operated with a specimen temperature of $60 \mathrm{~K}$, a pulse repetition rate of $200 \mathrm{kHz}$, and a pulse fraction of 0.2. Examples of three dimensional (3D) carbon atom maps and carbon concentration profiles showing austenite and ferrite regions are reported elsewhere for the same steel [9-11]. The concentration of carbon was determined from the number of carbon atoms compared to the total number of atoms in small slices perpendicular to one of the axes of a selected volume within austenite or ferrite regions with a random solid solution. Error bars for individual APT values represent the statistical scatter in the concentration profiles due to the number of ions in each slice of the selected volume of analysis. Mean values of a collection of APT measurements are also reported. In this case, their corresponding error bars are standard deviations of the mean value representing the dispersion of the data.

A transmission electron microscopy (TEM) image of the initial microstructure, consisting of nano-scale plates of bainitic ferrite, separated by carbon-enriched regions 
of retained austenite, is shown elsewhere [10]. The volume percentage of the austenite was determined to be $29 \pm 2 \%$. The retained austenite is sufficiently enriched with carbon (8.3 \pm 2.7 at. \% - a mean value of 8 APT measurements) to remain stable during cooling to ambient temperature, thereby avoiding transformation to martensite. The high carbon content of the ferrite in solid solution ( $0.66 \pm 0.24$ at.\% - a mean value of 9 APT measurements) in this nanostructured bainite is remarkable, and is well above that expected from PE with austenite (PE value of 0.12 at. \% C). More details on the characterization of this initial microstructure are summarized elsewhere $[9,10]$.

TEM examination revealed that tempering for $1 \mathrm{~h}$ at $400{ }^{\circ} \mathrm{C}$ did not introduce any appreciable change in the original microstructure [11]. Extremely fine plates of ferrite and thin films of retained austenite were observed and the austenite volume percentage did not change (29 $\pm 1 \%)$. Corresponding APT results showed that the carbon content in the austenite (5.16 \pm 0.88 at. \% - an individual APT value) and in the ferrite $(0.57 \pm$ 0.35 at. \% - an individual APT value) were similar to that measured in the initial microstructure. Additional carbon enrichment of untransformed austenite was not observed. After tempering at $450{ }^{\circ} \mathrm{C}$ for $30 \mathrm{~min}$., some of the retained austenite decomposed into cementite and ferrite. Additionally, the volume percentage of austenite decreased from $29 \pm 1 \%$ to $2 \pm 1 \%$ according to X-ray diffraction analysis. At this temperature, precipitation of $\varepsilon$-carbide in ferrite was detected by both TEM and APT [11].

As mentioned previously, a high carbon, high silicon alloy was studied in ref [11] and in the current study, whereas recent Q\&P investigations have been performed on a low carbon, high silicon alloy [7]. It is interesting to note that increased austenite fractions were generally obtained for specimens after intercritical annealing, rather than after full austenitizing, prior to Q\&P processing. The increased austenite fractions may be associated with the higher initial austenite carbon content produced by the intercritical annealing [7]. Reduced austenite fractions after full austenitizing before Q\&P processing might also be explained by initial carbon segregation to dislocations in the martensite that formed from the lower carbon content austenite [7]. Reduced austenite fractions were also obtained after long partitioning times at $450{ }^{\circ} \mathrm{C}$ [7].

Based on these results [11], additional APT measurements of carbon in austenite and ferrite were performed for the initial microstructure and after tempering at $400^{\circ} \mathrm{C}$ and $450^{\circ} \mathrm{C}$ for 30 min., the results of which are listed in Table 1 . In general, the supersaturated ferrite did not appear to decarburize during tempering at either temperatures, i.e. the amount of carbon in solid solution in the ferrite after tempering was similar to that measured in the initial microstructure. Similar carbon content ranges were obtained for the austenite in the initial microstructure and after tempering at 400 ${ }^{\circ} \mathrm{C}$. Similar mean APT values were also obtained. The loss of carbon in austenite, due to carbide precipitation during tempering at $450{ }^{\circ} \mathrm{C}$, was also clearly evident.

The range of APT values observed for the amount of carbon in solid solution in the austenite in the initial microstructure and after tempering at $400{ }^{\circ} \mathrm{C}$ is remarkable. Carbon content values range from 4.8 to 12.1 at. \% in the initial microstructure and from 5.7 at.\% to 11.3 at. \% in the tempered microstructure at $400{ }^{\circ} \mathrm{C}$. This is a consequence of the austenite films being entrapped between neighbouring subunits of bainitic ferrite that have a higher carbon content than the blocks of residual austenite located between the sheaves of bainite [13].

Shelf et al. [14] quantitatively proved that carbon in austenite is distributed very inhomogeneously in a bainitic microstructure. Austenite lattice spacing measurements from TEM lattice fringes show a large variation from region to region [14]. More recently, direct quantitative proof for this behaviour was provided by APT in a medium 
carbon high silicon bainitic steel [15], where an average carbon content of $6.4 \pm 1.8$ at. $\% \mathrm{C}$ was observed in a 80-nm-thick austenite region, whereas an average carbon content of $9.8 \pm 0.4$ at. \% C was measured in a 3.5-nm-thick austenite film.

The APT carbon contents of the analyzed austenite regions listed in Table 1 are correlated with their thicknesses in the initial microstructure and after tempering at $400^{\circ} \mathrm{C}$ in Fig. 1. The higher APT carbon content values (from $\sim 8$ to $\sim 12$ at. \%) correspond to nano-scale austenite films $(10-50 \mathrm{~nm})$, as illustrated in Fig. 2. Austenite regions with lower carbon content (from $\sim 5$ to $\sim 8$ at. \%) correspond to thicker austenite films (greater than $50 \mathrm{~nm}$ ) or submicron blocky austenite, as illustrated in Fig. 2. The thickness of submicron austenite in some cases (see arrows in Fig. 1) may be higher than the values represented in this graph, since the full extent of the coarse features were not observed in the volume analyzed. An example of thick austenite is illustrated in Fig. 2 , where only a portion of a block of austenite was detected in the analysis volume. Beside the existence of non-uniform distributions of carbon in the retained austenite, the results in Fig. 1 confirm that additional partitioning of carbon from supersaturated ferrite to austenite after tempering at $400^{\circ} \mathrm{C}$ does not appear to occur for the film/lath features examined, i.e. the austenite stabilized with carbon during the bainitic heat treatment is not further enriched during tempering.

Carbon-enriched lath and film features were also observed in 3D carbon atom maps obtained from a low carbon, high silicon steel subjected to Q\&P processing [7]. If carbon-enriched retained austenite is assumed for these features [7], it is interesting to note that similar carbon levels are observed for the austenite from these different processing routes that involve carbon partitioning from supersaturated ferrite, albeit from silicon-containing steel alloys with vastly different bulk carbon content levels. It is also conceivable that the dislocation densities of the bainitic ferrite and the martensite differ. These significant differences in composition, processing, and microstructure perhaps warrant additional consideration.

The APT results from this study indicate that austenite carbon enrichment is achieved during the ten day bainitic heat treatment; additional carbon does not escape into the untransformed austenite during subsequent tempering. Also, higher carbon levels were observed for finer austenite features. It has been reported that as the austenite is refined, it becomes impossible to accommodate all the carbon that is rejected from the ferrite [16], and that the escape of carbon from supersaturated ferrite is initially limited by diffusion in ferrite, but is later controlled by diffusion in austenite [17]. Thus, the influence of the scale of the austenite and ferrite present in the microstructure might require further consideration.

Other competing reactions must be activated if carbon atoms in supersaturated ferrite do not partition to retained austenite during tempering at $400^{\circ} \mathrm{C}$. The presence of carbon accumulation randomly dispersed throughout the ferrite matrix during tempering at 400 ${ }^{\circ} \mathrm{C}$ for $30 \mathrm{~min}$. was also revealed in the studied steel using atom probe tomography [11]. It is likely that these carbon-enriched regions may signify the onset of the transition carbides observed during tempering at $450{ }^{\circ} \mathrm{C}$ for $30 \mathrm{~min}$. [11]. The origin of these carbon concentration fluctuations is currently under investigation, but they are believed to be associated with a redistribution of carbon to dislocations in bainitic ferrite [8]. Better understanding of possible reactions that compete for carbon, such as carbide precipitation, and the influence of dislocations in martensite are also of great importance with respect to Q\&P processing.

\section{Acknowledgement}


The authors gratefully acknowledge the support of the Research Fund for Coal and Steel and the Spanish Ministry of Science and Innovation for funding this research under the contracts RFSR-CT-2008-00022 and MAT2007 - 63873, respectively. Research at the Oak Ridge National Laboratory SHaRE User Facility was sponsored by the Scientific User Facilities Division, Office of Basic Energy Sciences, U.S. Department of Energy. AJC gratefully acknowledges support from Los Alamos National Security, LLC, operator of the Los Alamos National Laboratory under contract number DE-AC5206NA25396 with the U.S. Department of Energy and the Advanced Steel Processing and Products Research Center, a National Science Foundation Industry/University Cooperative Research Center at the Colorado School of Mines and the Inter-American Materials Collaboration Program.

\section{References}

[1] S Matas and RF Hehemann, Nature 187 (1960) 685.

[2] SJ Matas and RF Hehemann, Met Soc AIME -- Trans 221 (1961) 179.

[3] M Sarikaya G Thomas, JW Steeds, SJ Barnard, GDW Smith, in: HI Aaronson (ed.), Proceedings of an International Conference on Solid to Solid Phase Transformations, TMS, Warrendale, PA, 1982, pp. 1421-1425.

[4] JG Speer, DK Matlock, BC DeCooman, JG Schroth, Acta Mater 51 (2003) 2611.

[5] JG Speer, DV Edmonds, FC Rizzo, DK Matlock, Curr Opin in Solid State Mater 8 (2004) 219.

[6] DV Edmonds, K He, FC Rizzo, BC DeCooman, DK Matlock, JG Speer, Mater Sci Eng A 438-440 (2006) 25.

[7] A Clarke, Carbon partitioning into austenite from martensite in a siliconcontaining high strength sheet steel, $\mathrm{PhD}$ Thesis, Colorado School of Mines, Golden, CO, 2006.

[8] AJ Clarke, JG Speer, MK Miller, RE Hackenberg, DV Edmonds, DK Matlock, FC Rizzo, KD Clarke, E DeMoor, Acta Mater 56 (2008) 16.

[9] FG Caballero, MK Miller C Garcia-Mateo, Acta Mater, (2010) 2338.

[10] FG Caballero, MK Miller, SS Babu, C Garcia-Mateo, Acta Mater 55 (2007) 381.

[11] FG Caballero, MK Miller, C Garcia-Mateo, C. Capdevila, SS Babu, Acta Mater 56 (2008) 188.

[12] MK Miller, Atom probe tomography, Kluwer Academic/Plenum Press, New York, NY, 2000, p. 8.

[13] HKDH Bhadeshia, DV Edmonds, Acta Metall 28 (1980) 1265.

[14] PG Self, HKDH Bhadeshia, WM Stobbs, Ultramicroscopy 6 (1981) 29.

[15] FG Caballero, C Garcia-Mateo, MJ Santofimia, MK Miller, C Garcia de Andres, Acta Mater 57 (2009) 8.

[16] SA Mujahid and HKDH Bhadeshia, Acta Metall Mater 40 (1992) 389.

[17] M Hillert, L Hoglund, and J Agren, Acta Metall Mater 40 (1993) 1951. 


\section{Table Captions}

Table I. Carbon content in austenite and bainitic ferrite (at-\%) measured by APT

\section{Figure Captions}

Figure 1.- Carbon content in austenite measured by APT as a function of the thickness of the analyzed austenite regions in the initial microstructure and after tempering at 400 ${ }^{\circ} \mathrm{C}$.

Figure 2.- Examples of carbon atom maps and corresponding concentration profiles across austenite-ferrite interfaces for nano-scale films of austenite and sub-micron blocky austenite. $\alpha$ is bainitic ferrite and $\gamma$ is austenite. 


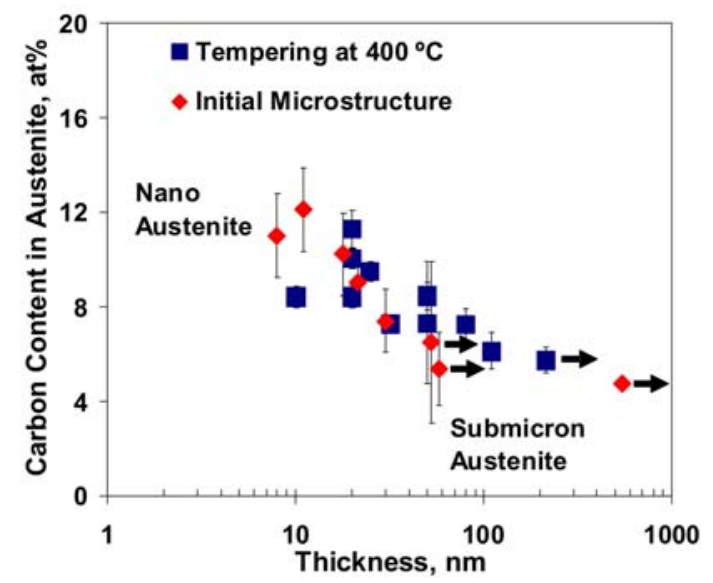

Fig1 


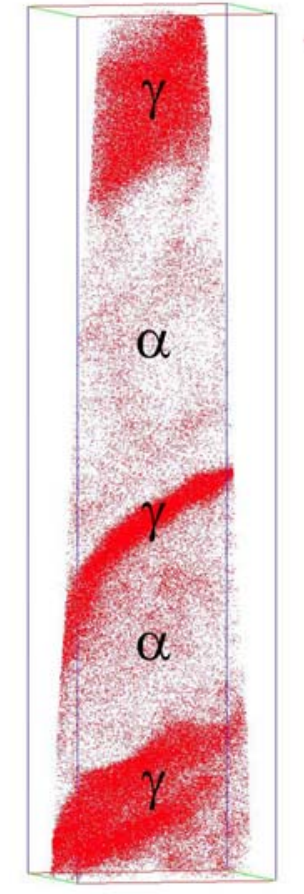

$\overline{20 n m}$
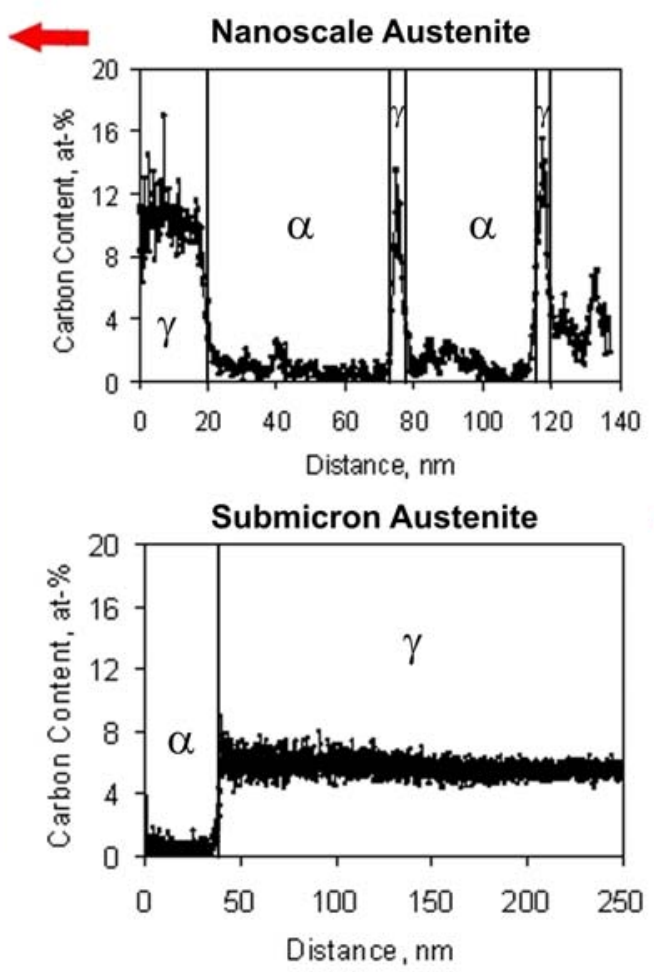

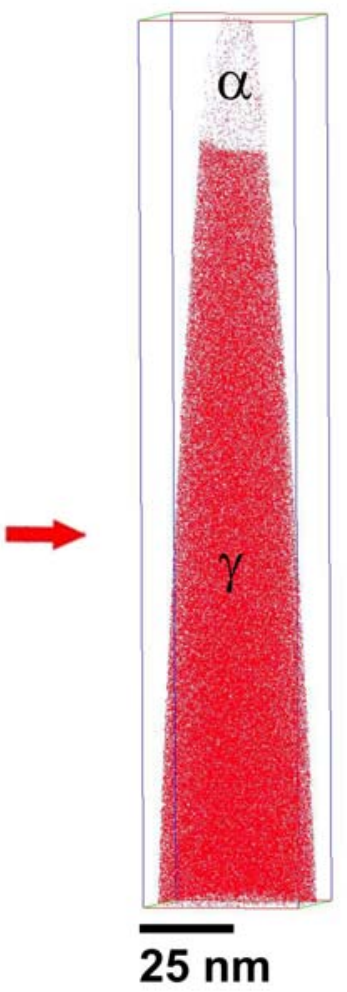

Fig2 
Table I. Carbon content in austenite and bainitic ferrite (at-\%) measured by APT

\begin{tabular}{|c|c|c|}
\hline Sample & Austenite & Bainitic Ferrite \\
\hline Initial Microstructure & $\begin{array}{l}6.50 \pm 3.40 \\
7.39 \pm 1.31 \\
5.38 \pm 1.52 \\
10.21 \pm 1.72 \\
11.00 \pm 1.78 \\
12.10 \pm 1.79 \\
9.01 \pm 0.79 \\
\underline{4.77 \pm 0.24} \\
\end{array}$ & $\begin{array}{l}0.71 \pm 1.13 \\
0.64 \pm 0.53 \\
0.99 \pm 0.75 \\
0.42 \pm 0.88 \\
0.17 \pm 0.54 \\
0.74 \pm 0.33 \\
0.61 \pm 0.20 \\
0.83 \pm 0.29 \\
\underline{0.85} \pm 0.339 \\
\end{array}$ \\
\hline Average & $8.30 \pm 2.70$ & $\overline{0.66 \pm 0.24}$ \\
\hline Tempering at $400^{\circ} \mathrm{C}$ & $\begin{array}{l}6.12 \pm 0.77 \\
7.32 \pm 2.55 \\
9.47 \pm 0.41 \\
10.02 \pm 0.43 \\
5.74 \pm 0.55 \\
11.27 \pm 0.79 \\
8.42 \pm 0.47 \\
8.40 \pm 0.42 \\
7.26 \pm 0.65 \\
8.45 \pm 0.57 \\
\underline{7.27 \pm 0.38} \\
\end{array}$ & $\begin{array}{l}0.11 \pm 0.49 \\
0.22 \pm 0.46 \\
0.77 \pm 0.83 \\
0.91 \pm 0.36 \\
1.02 \pm 0.59 \\
0.76 \pm 0.32 \\
1.00 \pm 0.50 \\
0.76 \pm 0.23 \\
1.04 \pm 0.39 \\
\end{array}$ \\
\hline Average & $8.16 \pm 1.65$ & $0.73 \pm 0.17$ \\
\hline Tempering at 450 & $\begin{array}{l}3.75 \pm 0.95 \\
4.19 \pm 1.26 \\
3.72 \pm 0.73 \\
3.89 \pm 0.26\end{array}$ & $\begin{array}{l}0.71 \pm 0.33 \\
0.57 \pm 0.51 \\
\underline{0.97 \pm 0.51} \\
0.75 \pm 0.20\end{array}$ \\
\hline
\end{tabular}

